\title{
MANIFESTACIONES DE LA VIOLENCIA POLÍTICA DE GÉNERO EN LAS CONTIENDAS ELECTORALES 2015 EN El ESTADO DE ChIAPAS. NotAs PARA El ANÁlisis
}

\author{
Manifestations of Political Gender Violence in the 2015 Electoral Contests in the State of Chiapas. \\ Notes for Analysis \\ Ramón Abraham Mena-Farrera \\ Juan Iván Martínez-Ortega \\ Ariadna Martínez-Olvera
}

\begin{abstract}
Resumen: Se presentaun estudio analítico con perspectiva de género paravalorar de quéformas se manifestóla violencia política de géneroen la contienda electoral de 2015 en el estado de Chiapas. Los insumos se obtuvieron en las redes sociales, a través de las cuales se dio seguimiento a las campañas electorales, la jornada electoral y la toma de posesión. Los hallazgos muestran que la simulación de los partidos politicos en el cumplimiento de la ley reproduce y acentúa la desigualdad de género en la política formal, produciendo nuevas formas de violencia sobre las mujeres cuya participación política resulta vulnerada.
\end{abstract}

Palabras clave: violencia de género, mujeres, igualdad de oportunidades, elecciones, participación política, redes sociales.

Abstract: This article presents results of an analytical study with a gender perspective that seeks to answer the question, What forms of political gender violence were manifested in the elections of 2015 in the state of Chiapas? Reports obtained from the wider social networks monitoring the electoral campaigns, elections, and the turnover (change over) of officials was analyzed. The manner in which political parties seemed to comply (apparently complied) with the law actually reproduced and accentuated gender inequality, and moreover produced new forms of violence against women whose political participation was violated.

Keywords: gender violence, women, equal opportunity, elections, political participation, social media.

\footnotetext{
Ramón Abraham Mena Farrera. Doctor en Ciencias Sociales y Humanísticas por el Centro de Estudios Superiores de México y Centroamérica de la Universidad de Ciencias y Artes de Chiapas, México y por la Universidad de Alicante, España. Técnico académico titular de El Colegio de la Frontera Sur, México. Temas de especialización: estudios de fenómenos sociotécnicos para su reflexión y comprensión desde la experiencia tecnológica. Correo electrónico: rmena@ecosur.mx.

Juan Iván Martínez Ortega. Maestro en Estudios para la Paz y el Desarrollo por la Universidad Autónoma del Estado de México. Técnico académico titular de El Colegio de la Frontera Sur, México. Temas de especialización: estudios de género, paz, violencias, participación política de las mujeres. Correo electrónico: jimartinez@ecosur.mx.
}

Ariadna Martínez Olvera. Licenciada en Psicología por la Universidad Autónoma Metropolitana-Xochimilco, México. Asistente de investigación de El Colegio de la Frontera Sur, México. Temas de especialización: masculinidades, violencia contralas mujeres, migración. Correo electrónico: avrilkat@gmail.com.

Enviado a dictamen: 10 de diciembre de 2015. Aprobación: 23 de septiembre de 2016.

Revisiones: 1 


\section{Introducción}

$\amalg$ n la ciencia política clásica se considera la polis griega como la primera forma de organización sociopolítica que construye una división de espacios sociales: la casa y lapolis. En el primero ocurre la vida cotidiana y las relaciones de parentesco, y quienes son amos, padres, varones y esposos son ciudadanos en la polis (Serret, 2008). En la consolidación del Estado moderno esas dos esferas pervivieron, la privada y la pública, la doméstica y la política; lo privado entendido como lo privativo, y lo público como lo que puede ser visto y oído por todos (Arendt, 1998). Este último es el lugar en el que se desarrollan las actividades que cuentan con reconocimiento social, tal es el caso de la actividad política.

Las exigencias y materialización de las demandas feministas propiciaron que las mujeres ingresaran a la esfera pública/política; se les permitió un acceso formal pero no se generaron las condiciones estructurales y culturales que les permitieran competir y acceder en condiciones equitativas. Ejemplo de ello es el caso de México, donde, aparentemente, con el otorgamiento de la ciudadanía a las mujeres - votar y ser votadas - seles permitía participar en la toma de decisiones. No obstante, la historia reciente demuestra que hay resistencias y obstáculos de facto para que ello ocurra. Al reconocer la desigualdad social y la desventaja histórica de las mujeres, surge la noción de equidad y con ello de las acciones afirmativas ${ }^{1}$ las cuotas de género - también en el plano de lo formal o normativo-, con lo que se obliga a los partidos políticos a postular determinado porcentaje de personas de un mismo género. ${ }^{2}$

En México ninguna mujer ha ocupado el cargo de presidenta de la República. En el poder legislativo, en la presente legislatura (2015-2018), la Cámara Baja está conformada por el 41.1\% de mujeres (Cámara de Diputados, 2015) y el Senado por el 34.3\% (Senado de la República, 2015a). En cuanto a las Secretarías de Estado, las mujeres ocupan 3 de 19, lo que equivale al 15.7\% (Presidencia de la República, 2015).

Para Chiapas, en la LXVI Legislatura votada en 2015 por primera vez las mujeres son mayoría: de un total de 41 curules, ellas ocupan 24. Sin embargo, son hombres quienes presiden la Mesa Directiva, la Junta de Coordinación Política y las Comisiones más importantes, esto es, Hacienda, Gobernación y Puntos Constitucionales y Justicia (Congreso del Estado de Chiapas, 2015). En cuanto a las Secretarías de Estado, de un total de 21 sólo en una de ellas una mujer es titular, se trata de la Secretaría de Hacienda ${ }^{3}$ (Gobierno del Estado de Chiapas, 2015). En las alcaldías, de 119 municipios considerados, ${ }^{4}$ las mujeres son presidentas municipales en 34 , lo que equivale al $28.6 \%$, aspecto que contrasta si se considera el total de integrantes de ayuntamientos porque, sumando síndicos y síndicas con regidoras y regidores en ese mismo número de municipios, resulta un total de 1840 cargos públicos en los cuales las mujeres representan el 56\% (IEPC, 2015); es decir, hay más mujeres en sindicaturas y regidurías, pero aún son minoría en la titularidad del ejecutivo municipal.

Los datos anteriores, sin ser exhaustivos, reflejan asimetrías y desigualdades en cuanto a la presencia de mujeres en los cargos de poder público y obstáculos para participar en la política formal..$^{5}$ Desde el ámbito académico se han realizado investigaciones que abordan las inequidades en los espacios de representación popular (Barrera, 1998a, 1998b; Massolo, 2003; Coutiño y Hernández, 2010; Fernández, 2014). En ellas se analizan las desventajas de las mujeres en la política y se recalca la importancia de legislar al respecto, aunque la igualdad política requiera además de logros jurídicos, escenarios reales de competencia equitativa por el poder (Coutiño y Hernández, 2010). En fechas recientes se ha propuesto la utilización del término "violencia política de género" como una categoría que da cuenta de dichas inequidades.

En este texto pretendemos responder a la pregunta: ¿de qué formas se manifestó la violencia política de género en la contienda electoral de 2015 en el estado de Chiapas? En el marco de este evento tuvo lugar un fenómeno conocido como "las Juanitas", ${ }^{6}$ además de otras formas de violencia contra las mujeres que participaron en aquellos comicios. Para responder a la pregunta planteada, inicialmente se presenta un 
breve marco conceptual, seguido del contexto, la explicitación del método utilizado, los hallazgos y algunas consideraciones finales.

Analizar un estudio de caso permite observar las particularidades de una situación que emerge y se presenta con intensidad en el marco de un contexto global relacionado con la particularidad; la desigualdad, discriminación y violencia política contra las mujeres. Una de las ventajas de los estudios de caso es que los datos pueden ser obtenidos desde una variedad de fuentes, tanto cualitativas como cuantitativas, a través de documentos, registros de archivos, entrevistas, observaciones o seguimientos (Chetty, 1996 en Martínez, 2006). De acuerdo con Yin (1989: 23 en Martínez, 2006), el estudio de caso es apropiado para temas que se consideran prácticamente nuevos.

\section{Marco conceptual}

\section{La violencia política de género como categoría explicativa}

Desde las instituciones y los movimientos sociales se ha visibilizado la violencia de género como un fenómeno que cuantitativa y cualitativamente se ejerce de forma más generalizada contra las mujeres; nos parece que el término más adecuado para referirse al fenómeno es "violencia de género en contra de las mujeres" (Lagarde, 2006 en Muñoz, 2011). Si bien es posible que no toda la violencia contra las mujeres sea violencia de género (Castro, 2012), lo que nos interesa del concepto citado es que da cuenta de que la construcción sociocultural del género se encuentra en la base de la justificación y legitimación de ciertos tipos de violencia ejercidos contra ellas.

Con la incursión de las mujeres en la esfera políticoelectoral, pero sin transformaciones de fondo en el sistema de dominación masculina, se reconfigura un nuevo tipo de violencia que puede ser denominado "violencia política de género", la cual se ejerce mayoritariamente contra las mujeres. Pero, toda vez que no son las únicas sujetos de género, el concepto tiene potencia suficiente para explicar manifestaciones de violencia dirigidas a diversas identidades sexo-genéricas.
Al utilizar la "violencia política de género" como categoría explicativa pretendemos que sirva para dar cuenta de aquellas situaciones, acciones y omisiones que impiden la participación equitativa de hombres y mujeres en las contiendas electorales. Es decir, si en la sociedad existe violencia de género contra las mujeres, la violencia política de género aparece como una expresión de la primera en un ámbito de la política, en este caso específico, durante las contiendas político-electorales.

\section{Rastreando el concepto}

Las primeras formulaciones de la violencia política de género o violencia política en razón de género como concepto se ubican en la Convención Interamericana para Prevenir, Sancionar y Erradicar la Violencia contra la Mujer "Convención de Belém do Pará", la cual explicita las formas en que se expresa tal violencia situándola como una más de "las relaciones de poder históricamente desiguales entre mujeres y hombres" (OEA, 1996: 75-76). En el año 2012, cuando se comenzó a utilizar el término con mayor recurrencia, María Eugenia Rojas Valverde constata y documenta conductas sistemáticas de acoso y violencia contra mujeres que ocupan cargos públicos en Bolivia (Rojas, 2012).

La Asociación de Concejalas de Bolivia (ACOBOL) publicó un documento denominado Violencia política por razón de género en el que desarrolla definiciones sobre "acoso político" y "violencia política". Define al acoso político como "el conjunto de actos de presión, persecución, hostigamiento o amenazas", y la violencia política como las "acciones, conductas y/o agresiones físicas, psicológicas, sexuales cometidas por una persona o grupo de personas" (ACOBOL, s.f.: 131). Ambas definiciones se refieren a acciones en contra de mujeres candidatas, electas, designadas o en ejercicio de la función político pública, o en contra de sus familias, con el propósito de acortar, suspender, impedir o restringir las funciones inherentes a su cargo, para inducirlas u obligarlas a que realicen acciones en contra de su voluntad, o incurran en omisiones en el cumplimiento de sus funciones o en el ejercicio de sus derechos. 
También en ese año se documentaron y publicaron casos relacionados con la discriminación, la manipulación y la violencia política en contra de mujeres en la esfera pública de dicho país. Ante ello, la ACOBOL demandó una mejora en las condiciones de participación política de las mujeres, la atención de casos de acoso y violencia política y la adopción de medidas para atender y enfrentar este tipo de situaciones (Machicao en Cerva, 2014).

En México, Cerva (2014) destaca la especificidad de un tipo de violencia de género que constituye una particular expresión de la discriminación hacia las mujeres: es cometido por una persona, por sí misma o a través de terceros, que viola los derechos de las mujeres, y que tiene como resultado impedir su participación en las mismas condiciones que los hombres en la vida política, social, económica y cultural en el "ejercicio de la representación política, para impedir, restringir el ejercicio de su cargo o inducirla a tomar decisiones en contra de su voluntad, de sus principios y de la ley" (Instraw en Cerva, 2014: 123). A ello lo caracteriza como "violencia política en razón de género".

Lo anterior, menciona Cerva, nos presenta un escenario sistemáticamente infranqueable para que las mujeres ingresen a la política, o bien para que su ingreso se lleve a cabo en desventaja: "no sólo se trata de desaliento, temor o amedrentamiento, sino concretamente es un impedimento que no pueden superar y se transforma en una barrera para el desarrollo de sus carreras políticas" (Bonder y Rodríguez en Cerva, 2014: 123).

Un año antes, en 2013, la senadora Lucero Saldaña del Partido Revolucionario Institucional (PRI) presentó una iniciativa para incluir la violencia política de género en la Ley General de Acceso de las Mujeres a una Vida Libre de Violencia y en el entonces Código Federal de Instituciones y Procedimientos Electorales (COFIPE). La iniciativa fue aprobada en el Senado y pasó a la Cámara de Diputados, pero ahí se detuvo. Tras la reforma político electoral de 2014, senadoras del Partido Acción Nacional (PAN) presentaron otra propuesta similar, y en 2015 senadoras y senadores de los tres partidos políticos mayoritarios volvieron a presentar la iniciativa sin que ésta haya sido aún aprobada — septiembre de 2016- Las únicas acciones en este sentido fueron dos exhortos del Senado fechados el 21 de abril de 2015, uno de los cuales “exhorta al Instituto Nacional Electoral, así como al Consejo Nacional para Prevenir y Eliminar la Discriminación a prevenir y, en su caso, sancionar a quien cometa cualquier tipo de violencia contra las mujeres que resulten ser candidatas a cargos de elección popular en el país" (Senado de la República, 2015b).

En el año 2013, en el Congreso de Chiapas, la diputada Mirna Camacho ${ }^{7}$ propuso una iniciativa de ley en contra de la violencia política hacia las mujeres en correspondencia con la iniciativa a nivel nacional. A decir de la legisladora, se esperaba que pudiera ser aprobada antes de que terminara la LXV Legislatura; sin embargo, para las fechas en que se celebraron los comicios de 2015 la iniciativa seguía esperando turno en las comisiones de Equidad de Género y Justicia para su dictaminación (Vázquez, 2015).

La prolongación en el tiempo para incluir la violencia política de género en la ley es una muestra de los obstáculos y las resistencias para visibilizar un fenómeno que va en aumento en la medida en que se incrementa la presencia de las mujeres en ámbitos en los que anteriormente no tenían posibilidades de acceso.

\section{Contexto del caso}

De acuerdo con Leonardo Valdés, un sistema electoral es el conjunto de medios, reglas y procedimientos a través de los cuales la voluntad de los ciudadanos y ciudadanas se transforma en órganos de gobierno o de representación política (Valdés, 1995). Para el caso mexicano, dichas reglas están contenidas en la propia Carta Magna, en la Ley General de Instituciones y Procedimientos Electorales y en la Ley General de Partidos Políticos, además de en otras leyes secundarias y normas intermedias. En cuanto a la organización del sistema electoral mexicano, se compone del Instituto Nacional Electoral (INE) ${ }^{8}$ como autoridad administrativa, el Tribunal Electoral del Poder Judicial dela Federación (TEPJF) ${ }^{9}$ como autoridad jurisdiccional encargada de impartir justicia, y la Fiscalía Especial para la Atención de los Delitos Electorales (FEPADE), encargada de investigar los delitos en la materia. 
El sistema electoral incluye el sistema de partidos, el cual Valdés entiende como el espacio de competencia por la obtención y el ejercicio del poder político (1995). En el caso de México, tienen registro a nivel nacional nueve partidos políticos, ${ }^{10}$ que están obligados a regirse al interior mediante tres documentos básicos entre los cuales están sus Estatutos." En todos los casos, los partidos políticos manejan en su normatividad interna un aparente compromiso y la obligación de postular candidatos de ambos sexos de manera paritaria, ya sea de forma explícita, como el Partido de la Revolución Democrática (PRD), que menciona la paridad vertical y horizontal, o de manera más ambigua, como el PAN, que menciona que cumplirán las reglas de equidad de género y otras acciones afirmativas que comprenda la legislación correspondiente (INE, 2016a).

En Chiapas tienen presencia cinco de los nueve partidos políticos nacionales -PAN, Partido Verde Ecologista de México (PVEM), PRD, Morena y PRI, Partido del Trabajo (PT), Partido Nueva Alianza, Partido Movimiento Ciudadano y Partido Encuentro Social-, pero además tienen registro dos partidos estatales: Chiapas Unido y Mover a Chiapas. Las elecciones las organiza la Junta local del INE, que es el Instituto de Elecciones y Participación Ciudadana (IEPC). La legislación local es explícita en cuanto a la paridad; de hecho, el apartado B del artículo 17 de la Constitución local establece: "La ley garantizará que en la postulación y registro de candidatos a diputados del Congreso del Estado y a integrantes de los ayuntamientos, los partidos garanticen la paridad de género". ${ }^{12}$ En el estado, las elecciones de 24 diputados y diputadas en igual número de distritos electorales, más 16 según el principio de representación proporcional más uno en una circunscripción plurinominal especial para la representación migrantes en el extranjero - 41 en total-, e integrantes de los 122 Ayuntamientos, se celebrarán el tercer domingo de julio del año de la elección. Para la elección del 19 de julio de 2015 en la entidad federativa se inscribieron 13000 aspirantes (Rodríguez, 2015), en los cuales se incluye el registro de candidatos independientes hombres para contender por alcaldías en los municipios de Ángel Albino Corzo,
Francisco León, Palenque, San Fernando, Tapachula, Tecpatán, Tuxtla Gutiérrez y Venustiano Carranza y un aspirante a diputado hombre para el distrito dos".

Antes, durante y después de la jornada electoral distintos medios de comunicación electrónica e impresa, así como organismos de la sociedad civil, denunciaron a través de blogs, videos y espacios en las redes sociales -Facebook, Twitter y YouTubeirregularidades relacionadas con violencia dirigida hacia las mujeres que contendían por algún cargo público. Tales acciones se acrecentaron conforme se acercaba el día de la elección.

Además de ello, en el registro de candidatos y candidatas los partidos políticos no cumplieron con la paridad que les exigía la ley; el PRI registró 102 aspirantes a alcaldes hombres y 14 mujeres; el PVEM 106 y 14; el PRD 73 y 26, y el PT 63 y 5, respectivamente (García, 2015). Ante ello, hubo denuncias y reclamos de organizaciones civiles como la Red Chiapas por la ParidadEfectiva (REPARE). El TEPJF emitióla sentencia SUP-REC-294-2015 por la que se obligaba a los partidos políticos a suspender las campañas hasta que cumplieran la paridad de género.

Tal situación propició que los partidos sustituyeran a candidatos hombres por mujeres con quienes tenían vínculos filiales, "las Juanitas". Dicho fenómeno ha sido estudiado, entre otros, por Delgado (2016), Mixtega (2002), Báez (2014) y Souza (2015), quienes lo definen como "una práctica política en México que consiste en simular candidaturas de mujeres que, en caso de ganar, renuncian al cargo para dejar que asuma el suplente varón, quien generalmente es el esposo o un familiar de la candidata" (Delgado, 2016: 196).

\section{Método}

El presente trabajo es un estudio cualitativo con perspectiva de género en el que se analizan las manifestaciones de violencia política de género contra las mujeres en las elecciones de ayuntamientos y diputaciones locales del estado de Chiapas. Escualitativo en la medida en que pretendemos conocer el conjunto de cualidades interrelacionadas que caracterizan el 
hecho social (Valles, 2000); la perspectiva de género la entendemos como aquella:

[...] basada en la teoría de género que permite analizar a las mujeres y a los hombres no como seres dados, eternos e inmutables, sino como sujetos históricos, construidos socialmente, productos del tipo de organización social de género prevaleciente en su sociedad. La teoría de género ubica a las mujeres y a los hombres en su circunstancia histórica y por ello da cuenta también de las relaciones de producción y de reproducción social como espacios de construcción de género [...] Con la perspectiva de género es posible saber cómo se construyen día a día, institucional e informalmente, el machismo, la violencia o la increíble capacidad de tolerancia y respuesta de las mujeres a la miseria (Lagarde, 1997: 31-33).

Los insumos del estudio son relatos obtenidos de las redes sociales de mayor alcance por medio de las cuales se dio seguimiento a las campañas electorales -16 de junio al 15 de julio-, la jornada electoral del 19 de julio y la toma de posesión del l de octubre de 2015. Se analizaron más de 96 relatos, ${ }^{13}$ notas periodísticas, audios y videos que circulan en internet por medio de blogs, YouTube, Facebook y las versiones electrónicas de periódicos nacionales y locales. ${ }^{14}$

Los relatos fueron sistematizados y categorizados utilizando el software cualitativo QSRN6. Para el análisis se consideraron las dimensiones propuestas por Joan Scott, para quien el género es un elemento constitutivo de las relaciones sociales y de poder que comprende cuatro elementos interrelacionados, de los cuales ninguno opera sin los demás: a) las representaciones simbólicas, b) los conceptos normativos, c) referencias a las instituciones y organizaciones sociales, y d) la identidad subjetiva (Scott, 1996).

En el seguimiento de la información que fluía por internet, se evidenció la violencia que los multimedios documentan y reproducen, además de la interactividad con las personas que leen las notas, dejan comentarios y las distribuyen por sus propias redes. Coincidimos con Groebel, para quien los medios son utilizados como una confirmación adicional de sus creencias y actitudes (Groebel, 1999: 16); por ello, consideramos que las líneas discursivas recabadas - notas, videos y audios - por sí mismas tienen una intencionalidad y pueden ser parte de la violencia contra las mujeres.

\section{Hallazgos}

El fenómeno de "las Juanitas" de Chiapas generó más de 165000 menciones en Google, el motor de búsqueda de mayor alcance en internet. Es un número alto si tomamos en cuenta que el anuncio del triunfo del gobernador de Chiapas en 2012 en el mismo buscador tuvo 471000 menciones. Aunque el fenómeno de "las Juanitas" tuvo una vida efímera en la red, la noticia alcanzó un carácter viral porque contó con un alto tráfico antes, durante y después de acontecido, y dejó un amplio rastro en publicaciones, fotos, caricaturas, videos y audios. El análisis elaborado mediante los datos ofrecidos en los portales electrónicos del Instituto de Elecciones y Participación Ciudadana (IEPC), el Programa de Resultados Electorales Preliminares (PREP) y la REPARE fue contextualizado tomando en cuenta notas periodísticas de internet, relatos en blogs, videos de las campañas y entrevistas en YouTube.

En la tabla 1 se presenta el universo analizado para este estudio. Inicialmente, en el PREP aparecían 38 mujeres como ganadoras, ${ }^{15}$ de las cuales 34 fueron ratificadas como tales. Documentamos que en por lo menos 36 casos se presentaron manifestaciones de violencia política contra las mujeres, de las cuales destacamos las más significativas a partir de notas periodísticas en internet, denuncias en blogs, videos en YouTube y opiniones en Facebook (ver tabla l).

Fue posible identificar la caracterización del fenómeno con base en las cuatro dimensiones propuestas por Scott que a continuación se desglosan.

\section{a) Los símbolos culturales disponibles}

Para Joan Scott, el género como elemento constitutivo de las relaciones sociales comprende "símbolos culturalmente disponibles que evocan representaciones 
múltiples (y a menudo contradictorias) [...] mitos de luz y oscuridad, de purificación y contaminación, inocencia y corrupción. Para los historiadores, las preguntas son respecto a las representaciones simbólicas que se evocan, cómo y en qué contextos" (Scott, 1996: 289). A partir de los relatos recabados, se documentaron casos como el de Olga Gómez López, quien fue postulada por el PRI y ganó la presidencia municipal de Chanal. Además de hostigamientos y amenazas contra la candidata electa, un sector de la población organizó manifestaciones y bloqueos de calles. "Una causa de este problema que ha puesto en riesgo a la candidata, es la resistencia de la población a ser gobernada por una mujer, apreció la consejera Margarita Esther López, en una conferencia de prensa donde se mencionó a Chanal como un municipio en situación compleja” (Rodríguez, 2015). El hecho de que los pobladores manifiesten resistencia a ser gobernados por una mujer refleja obstáculos culturales que naturalizan la presencia de las mujeres en el ámbito privado, además de que ven como una transgresión el que figuren en la esfera pública; sin generalizar, en México, y en particular en Chiapas, son muy comunes los contextos en los que se considera que las mujeres deben obedecer y son los hombres quienes deben mandar (Pérez, 2004).

Otro caso que llama la atención es el sucedido a Magdalena Gabriela Santiago Figueroa, quien, siendo candidata a síndica en el municipio de Jiquipilas, cumplía con el perfil adecuado - trayectoria y capital político - para ser candidata a presidenta municipal cuando el partido se vio obligado a hacer las sustituciones: "Están pidiendo una mujer y yo soy mujer, están pidiendo que quieren ganar y yo la puedo ganar [...] ¿Qué más queremos para que el PRI gane?" (Mariscal, 2015). Sin embargo, no fue postulada porque no garantizaba renunciar cuando obtuviera el triunfo.

Lo anterior refleja obstáculos para una plena participación política de las mujeres. Por un lado se abren espacios a los que no tenían acceso, pero, por otro, las jerarquías más altas en esos espacios siguen siendo restringidas para ellas. Perdura la representación simbólica de que una mujer -incluso autónoma- no puede ser quien mande. En otro contexto, Xóchitl Gálvez comenta un caso en el estado de Hidalgo en el que un presidente municipal, en reunión con delegados de las comunidades, les decía: "Ustedes son hombres, ¿verdad? ¿A poco les gustaría que una mujer los mandara en su casa?" (García, 2015).

Si las mujeres, en el imaginario social, no pueden mandar en lo doméstico porque al hacerlo retarían la virilidad del hombre de la casa - padre, hermano, esposo- y con ello transgredirían el "orden natural", menos pueden hacerlo en la política, que es por excelencia un espacio de hombres, en el que las prácticas, normas y hábitos se han producido y reproducido a partir de códigos masculinos (Peschard, 2003).

\section{b) Los conceptos normativos}

Para Joan Scott (1996) los conceptos normativos se expresan en doctrinas religiosas, educativas, científicas, legales y políticas, que afirman categórica y unívocamente el significado de varón y mujer, masculino y femenino: “[...] la posición que emerge como predominante es expuesta como la única posible" (Scott, 1996: 289-290). En los relatos recabados, se hicieron patentes casos como el de Rosa Pérez Pérez, postulada por el PVEM en el municipio de Chenalhó, quien fue acusada de fraude cuando los resultados le favorecieron. "Tras encontrar las urnas con boletas, las cuales aseguran haber sido robadas por el Partido Verde [los lugareños...] exigieron celebrar un nuevo proceso electoral, en caso contrario, de acuerdo a los usos y costumbres impedirán la toma de protesta de Rosa Pérez Pérez" (Hernández, 2015).

En el caso citado, se observa la pretensión de una postura que se plantea como la única posible; es decir, si mediante los recursos legales-electorales no se satisface la exigencia de un sector de la población, se acude a los usos y costumbres y a la posibilidad que ello proporciona de imponer la voluntad de un grupo en particular. En este caso, utilizando los términos de Scott (1996), se trata de una doctrina política —usos y costumbres - que asigna significados cargados de 
valores a actos concretos. Un hecho similar sucedió en Mazapa de Madero, donde una investidura y toma de protesta fue asaltada para "poner a cada quien en su lugar":

Comenzado el evento, de forma grotesca y prepotente, le arrebató el micrófono a Roger Ultrilla Roblero, representante personal de Juan Carlos Gómez Aranda, secretario general de gobierno del estado, para tomarse él mismo la protesta de ley como presidente municipal de Mazapa de Madero 2015-18 y nombrar a Yulena López González, como presidenta del DIF municipal (Pérez, 2015).

En este caso, quien ganó la elección fue Yulena López, pero es su esposo el que ejerce las funciones de presidente municipal, y a ella la nombró presidenta del DIF permitiéndole aparecer sólo en actos protocolarios con el gobernador. Es habitual que las esposas de los presidentes municipales sean colocadas en ese cargo porque es la instancia que se ocupa de la asistencia social; es decir, son funciones relacionadas con el "cuidado a otros", por lo que se consideran actividades más cercanas a las mujeres (Lagarde, 1997). De esta manera, se puede observar que en la política, como en otros ámbitos, también existe una segregación ocupacional en función del sexo biológico.

\section{c) Las instituciones y organizaciones sociales}

En esta dimensión Scott incluye, además de la familia, el mercado de trabajo, la educación y las instituciones políticas, todas ellas como partes importantes en el proceso de construcción del género (Scott, 1996). Para efectos del caso que nos ocupa, si bien reconocemos la trascendencia de la escuela y el mercado en la reproducción del orden social, y en este caso de la violencia como parte de ese orden, los relatos recabados dan cuenta - por lo específico del caso - de cómo las instituciones e institutos políticos - partidos-, lejos de garantizar contiendas equitativas, son utilizados como instrumento para la violación de los derechos políticos de las mujeres. Por ejemplo:
Al Partido Verde Ecologista de México no le costó mucho decidir qué candidatos de la Costa sacrificar, pues era evidente dónde su caballada estaba flaca. Muy flaca. Los aspirantes más débiles de esta región fueron bajados por decisión unánime, Rigo López de Unión Juárez y Manuel Cruz Coutiño de Villa Comaltitlán. El jefe tucán optó por darles "palo", para darle cumplimiento a la paridad de género que emplazó el Tribunal Federal Electoral a las autoridades electorales estatales, pero también por debiluchos e intrascendentes. Desde ayer en Unión Juárez empezó a "campañear" la candidata Claudia Argelia Barrios, quien sólo tendrá cuarenta y ocho horas para tratar de enderezar un barco que está más que hundido. De por sí el escenario le favorecía al candidato de Acción Nacional, Gerardo Garrido Agustín, ya ni se diga ahora que se quedó con el camino libre (Victorio, 2015).

En relatos como el anterior se aprecia que las estructuras de los partidos políticos no son puestas al servicio de la sociedad, por el contrario, sirven para favorecer intereses de un grupo reducido de personas; si la ley los obliga a conducirse de una manera en la que sus intereses son trastocados, utilizan los recursos partidarios para diseñar formas en las que "simulan" cumplir con la ley; esa simulación reproduce y acentúa la desigualdad de género en el terreno de la política partidaria, pero además produce nuevas formas de violencia contra las mujeres, cuya participación política resulta vulnerada. Otro caso en el que se utilizan las instituciones para acentuar y reproducir las relaciones de poder asimétricas entre los géneros se observa en la integración de las comisiones en la recién electa legislatura (2015-2018) de Chiapas:

A pesar que en esta legislatura las mujeres son mayoría, las diputadas quedaron desplazadas para presidir las comisiones legislativas que discuten los temas relacionados con el presupuesto, impartición de justicia y políticas de gobierno en el estado [...] En contraparte, las comisiones de Equidad de Género, Artesanías y la Comisión de Atención a la Mujer y 
la Niñez fueron conformadas en su totalidad por mujeres. Ninguno de los diputados hombres que enarbolaron la bandera del empoderamiento de las mujeres durante su campaña quiso sumarse a estas comisiones (De los Santos, 2015).

Daniela Cerva (2014) se refiere a los partidos políticos como organizaciones generizadas. En el ejemplo citado se aprecia que por lo común las instituciones impregnadas de la política partidaria son generizadas y generizantes, pues no sólo se conducen conforme a concepciones tradicionales de los roles de género, sino que además alimentan y perpetúan esas concepciones. En Chiapas, las estructuras gubernamentales se caracterizan por su funcionamiento jerárquico y vertical (Castro, 2001).

\section{d) La identidad subjetiva}

Los cuerpos que encarnan las experiencias relacionadas con la jerarquía y verticalidad en la política configuran lo subjetivo de las mismas. Es decir, no es lo mismo que un hecho le suceda a un hombre que a una mujer, como no es lo mismo que quien o quienes lo evalúen sean hombres o mujeres. De ahí la importancia de tener en cuenta el carácter editorial de las notas utilizadas en este texto, puesto que los autores pretendemos aproximarnos a la comprensión del suceso desde lo que se dice discursivamente de él y no desde la voz de la experiencia de quien edita la nota. Barreto y colaboradores señalan al respecto que: “[...] independientemente de quien sea el autor del discurso, en una situación de violencia política, éste es construido con una finalidad que va más allá de usar el lenguaje para informar o comunicar ideas, éste busca interactuar de manera persuasiva frente al lector o el escucha" (2009: 739).

El fenómeno estudiado presenta una paradoja, pues obligar a los partidos a cumplir con la paridad y la consecuente sustitución de los hombres por candidatas "accesorio"16 — las Juanitas - propició que estas mujeres fueran utilizadas a voluntad de quien las necesitaba en un momento dado; y cuando dejaron de ser útiles, fueron desechadas. Tales acciones están avaladas por un sistema de creencias culturales que hace que los hombres - padres, esposos, jefescrean tener el legítimo derecho de dirigir la vida de las mujeres en todos los ámbitos (Martínez, 2007). Estas mujeres, cercanas a los líderes políticos, fueron obligadas o instadas a prestar su nombre y su cuerpo para cumplir una sentencia de paridad. Se usaron sus cuerpos con un objetivo particular y, después, se quiso prescindir de ellos para que cumpliesen otra función. Los relatos recabados dan cuenta de que ello fue negociado y pactado entre los dirigentes de los partidos -hombres-:

En el caso de la priista Magdalena Gabriela Santiago Figueroa, quien era candidata a síndica de Jiquipilas y a quien se ofreció contender por la Presidencia Municipal [...] pero a condición de que después abriera el camino para que asumiera como alcalde Rafael Fernando Farrera Esponda, uno de los "damnificados" por la sentencia del TEPJF. Así lo expresó el propio Farrera Esponda a Santiago Figueroa en una conversación telefónica a la que CNN México tuvo acceso. "Me habló el senador (Roberto Albores Gleason, presidente del PRI en Chiapas) y me dijo: 'No te preocupes porque van a tener el apoyo del gobernador (Manuel Velasco Coello, militante del PVEM). Él los va a impulsar otra vez. Hay una propuesta de que ganemos y luego nos va a subir a la Presidencia (municipal). Eso está apalabrado. Me dijo sólo: pon a una persona ahí (una mujer)", se escucha relatar al excandidato. En la conversación, Santiago Figueroa cuestiona a su compañero por qué no la dejan contender para ser alcaldesa, si ella era la candidata a síndica, es mujer y tiene trabajo político en la región. "Están pidiendo una mujer y yo soy mujer, están pidiendo que quieren ganar y yo la puedo ganar [...] ¿Qué más queremos para que el PRI gane?", revira Santiago Figueroa. Farrera Esponda le contraofrece quedar como regidora, un cargo menor. "El senador me dijo: 'Usted quede de síndico porque usted va a subir (a alcalde). Lo van a hacer (nombrar) en el Congreso y en el Cabildo [...] Yo me encargo de que usted suba", agrega el priista al reportar la charla 
que a su vez tuvo con su dirigente partidista. Pero Santiago Figueroa declina participar. "Es un engaño que le vamos a hacer a la gente y a mí no me parece. Lo más correcto es que yo subiera porque soy mujer y he trabajado mucho", menciona. Al final, en el registro de candidaturas quedó como candidata del PRI a la presidencia municipal de Jiquipilas María Magali Farrera Esponda, hermana de Rafael Fernando, quien ocupa la segunda posición como candidato a síndico municipal (Mariscal, 2015).

\section{Las formas en que se manifiesta la violencia política de género}

Los relatos recabados de denuncias en redes sociales muestran con claridad el incremento de la violencia física y psicológica hacia las mujeres participantes en las contiendas electorales; además, también se encontraron casos en los que ésta se ejerció a través de terceros e incluso mediante las redes sociales. Las denuncias fluyen de forma paralela al reconocimiento de que existe violencia contra las mujeres por razones políticas. Ello tiene dos implicaciones: por un lado, se están reconociendo como violentas ciertas experiencias que no habían sido leídas como tales (Canseco, 2015) $\mathrm{y}$, por otro lado, la poca o nula garantía que tienen las mujeres para participar en política sin sufrir actos que vulneren su actuar.

Le taparon los ojos, la sujetaron del cuello y le metieron los dedos en la boca causándole asfixia, la golpearon en diferentes partes del cuerpo, estómago, senos y partes íntimas, advirtiendo que sólo era un aviso para que se retirara de la contienda electoral (Rodríguez, 2015).

De manera más específica, en los relatos se identificaron casos en los que se retiró la propaganda de las candidatas, así como amenazas de muerte, descalificativos y agresiones físicas que varían en grados e intensidades. La violencia no sólo fue directa o interpersonal, también se presentó mediada por las estructuras e instituciones, ${ }^{17}$ en sintonía con el conjunto de ideas e imaginarios que prevalecen en la sociedad respecto al papel y los espacios que deben ocupar las mujeres en la sociedad por su condición de género. Al respecto, estas acciones se articulan como una tecnología de género, es decir, un efecto compuesto de representaciones discursivas y visuales que reproducen relaciones y posiciones de género en la vida cotidiana e institucional (De Lauretis, 1989).

\section{Reflexiones}

El fenómeno se caracterizó por múltiples elementos, entre ellos, la negativa inicial de los partidos políticos a cumplir paritariamente con las candidaturas, la desigualdad de condiciones entre hombres candidatos y mujeres que los sustituirían para las contiendas electorales a raíz del fallo del Tribunal, y la recepción violenta de dichas sustituciones en distintos niveles: personal, institucional - partidos políticos-, comunitario y social-cultural. Esto se debe, entre otros factores, a que la incursión de las mujeres en la política formal es relativamente reciente. Si no se hablaba de violencia política de género era, como explica Cerva (2014), porque las experiencias se consideraban como hechos aislados y no como una posible pauta de comportamiento en la experiencia política. Esto no puede considerarse como excusa para que el Estado no garantizara la seguridad de las mujeres en la anterior contienda electoral.

Sin embargo, no hay que perder de vista que las mujeres aludidas tienen capacidad de agencia y, por ende, reaccionan en la medida de sus posibilidades e intereses. Asimismo, hay que considerar los contextos en los que se presentó con mayor recurrencia la violencia política de género; es decir, hay municipios que se consideran más importantes que otros, ya sea por el presupuesto que manejan o por condiciones históricopolíticas, como San Cristóbal de Las Casas o Tuxtla Gutiérrez, en donde las candidaturas de los partidos más representativos estaban encabezadas por hombres. Habría sido interesante que la sustitución se diera, por ejemplo, en la contienda por la presidencia municipal de la capital chiapaneca.

Las iniciativas que se han propuesto para incluir la violencia política en la Ley General de Acceso de las 
Mujeres a una Vida Libre de Violencia han quedado en exhortos; son iniciativas que no se concretizan. Es posible que una de las razones sea porque se piensa que la violencia se da principalmente en el ámbito de lo privado, pero cuando tiene lugar en la esfera públicapolítica, su reconocimiento se dificulta debido a que los responsables de esa violencia ya no son el marido golpeador, el vecino o el familiar, sino los institutos e instituciones públicas y sus dirigentes, quienes son responsables, ya sea porque la ejercen, o porque son incapaces de evitar que se ejerza.

Si bien las leyes responden a demandas sociales, presentan serias limitaciones e incapacidad de anticipar las nuevas formas de violencia que se generan a partir de la aplicación de normas que demandan la disminución de las desigualdades. Las cuotas y la paridad en otros contextos han generado resultados satisfactorios; sin embargo, en el caso de Chiapas la pseudoaplicación de una reforma pensada progresista propició que la violencia se manifestara de otras formas. Ello sugiere ante las reformas a las leyes electorales, y en general en los marcos jurídicos relacionados con la igualdad entre hombres y mujeres, que es necesario prever los posibles impactos al aplicar la norma, dadas las resistencias de los partidos políticos para cumplir con las exigencias de paridad en la postulación de candidaturas.

La violencia no es estática, es algo inasible y sólo se puede observar por medio de sus manifestaciones, las cuales varían en formas, grados e intensidades. También se asumen, se piensan, se sienten de diferentes formas. Cuando se aprueba una ley, la violencia se reconfigura, por lo que las formas y expresiones aparecen, a veces, de maneras más sutiles, o, por el contrario, son más brutales. Mientras se pretenda erradicar la violencia orientando los esfuerzos a sus expresiones y no a sus causas -estructurales, culturales, enraizadas-, difícilmente se logrará la equidad y la igualdad en las contiendas políticas.

Consideramos que el término "violencia política de género" tiene potencia explicativa para dar cuenta de la desigualdad, inequidad y obstáculos que impiden la participación política de las mujeres en condiciones equitativas en las contiendas electorales. No obstante, reconocemos que presenta limitantes en cuanto a cómo se ha venido utilizando y cómo lo utilizamos en el presente texto; es decir, el concepto como tal se enfoca únicamente en ámbitos, personas y acciones presentes en la política formal electoral partidaria, pero no considera otras formas de participación política que ocurren, por ejemplo, en los movimientos sociales o en las organizaciones de la sociedad civil, en los que el acoso y otras formas de violencia motivadas por razones políticas también se presentan.

De manera preliminar, en este texto se da cuenta de la violencia política de género como un mecanismo sistemático que operativiza la anulación política de las mujeres. Con este esfuerzo inicial se pretende abonar al método, la teoría y la comprensión de los procesos de exclusión y violencia contemporáneos a partir de un caso particular, las contiendas electorales de Chiapas en 2015, que resulta relevante porque fue un espacio y momento en el que se crearon, reprodujeron e interactuaron hechos, discursos, representaciones e imágenes de la violencia política de género. También se pretende contribuir a una nueva forma de producir datos a partir de lo observado, señalado y debatido en fuentes escritas, visuales y multimedia en la red de internet. Se trata de un recurso hasta ahora poco visible y poco estudiado, donde la sociedad construye discursos, representaciones y prácticas de la violencia.

\section{Notas}

${ }^{1}$ Medidas de carácter temporal encaminadas a acelerar la igualdad entre hombres y mujeres, las cuales tienen por objeto eliminar las desventajas estructurales de las mujeres para una participación equilibrada con los hombres en todas las esferas de la sociedad (Medina y Benítez, 2010).

2 En el caso de México, las cuotas de género se han incrementado de manera gradual; en 1993 el Código Federal de Instituciones y Procedimientos Electorales (COFIPE) estipulaba que los partidos políticos debían "promover" una mayor participación de las mujeres en la vida política del país a través de su postulación a cargos de elección popular. En 1996 se reformó el COFIPE 
para establecer que se debía "considerar" que en los estatutos de los partidos las candidaturas a diputados y senadores no excedieran el 70\% para un mismo género. La reforma de 2002 también estableció la cuota del $30 / 70 \%$, pero esta vez estipulando que debía cumplirse en las candidaturas propietarias, dado que antes los partidos eludían la responsabilidad postulando a mujeres únicamente en las suplencias. La reforma de 2007 incrementó la cuota a 40/60\% procurando llegar a la paridad (Aparicio, 2011). Finalmente, la reforma de 2014 elevó a rango constitucional la paridad (50/50\%) como obligación de los partidos políticos en la postulación de candidatos y candidatas a puestos de elección popular, de manera que logró mayor grado de especificidad a partir de jurisprudencias emitidas por el Tribunal Electoral del Poder Judicial de la Federación.

${ }^{3}$ De acuerdo con información oficial de sus páginas web, dos Secretarías no tienen titulares, entre ellas la de Desarrollo y Empoderamiento de las Mujeres (Gobierno del Estado de Chiapas, 2015).

${ }^{4}$ Son 122 municipios, pero falta por resolverse la situación política de los restantes.

${ }^{5}$ Dalia Barrera Bassols distingue entre política formal e informal; la primera se refiere a "la participación en los tres poderes del gobierno, en los tres niveles (federal, estatal y local), así como la inserción en los órganos de representación popular y la pertenencia a los diversos partidos políticos [...] La participación política considerada informal sería la que tienen las mujeres en movimientos sociales, organismos no gubernamentales (ONGs), etc." (Barrera, 1998a: 289).

${ }^{6}$ Se denomina "Juanitas" a las mujeres que son postuladas por algún cargo político y una vez obtenido el triunfo renuncian en favor de otras personas, que generalmente son hombres, familiares o personas cercanas a ellas. "Juanito" es el alias de Rafael Acosta Ángeles, candidato en 2009 del Partido del Trabajo (PT) a jefe delegacional de Iztapalapa, a quien Andrés Manuel López Obrador le manifestó públicamente su apoyo con la condición de que una vez que obtuviera el triunfo renunciara en favor de Clara Brugada, quien pretendía postularse por el Partido de la Revolución Democrática (PRD) pero se le negó la candidatura.
${ }^{7}$ Diputada local por el PAN en la LXV Legislatura (20122015), presidenta de la Mesa Directiva en el periodo de marzo a octubre de 2014 y presidenta de la Comisión de Planeación del Desarrollo.

${ }^{8}$ En las 32 entidades federativas cuenta con juntas locales y en los 300 distritos electorales federales cuenta con juntas distritales ejecutivas (INE, 2016b).

${ }^{9}$ Está constituida por una Sala Superior y las seis Salas Regionales de Guadalajara, Monterrey, Xalapa, Distrito Federal, Toluca y especializada -en el Distrito Federal- (TEPJF, 2016).

${ }^{10}$ Partido Acción Nacional (PAN), Partido Revolucionario Institucional (PRI), Partido de la Revolución Democrática (PRD), Partido Verde Ecologista de México (PVEM), Partido del Trabajo (PT), Movimiento Ciudadano (MC), Nueva Alianza (NA), Morena y Encuentro Social (INE, 2016c).

${ }^{11}$ Los otros dos son el Programa de Acción y la Declaración de Principios.

${ }^{12}$ Constitución publicada en el Periódico Oficial del Estado, núm. 309 del 27 de junio de 201l. Decreto núm. 263. Última reforma mediante decreto núm. 514 publicada en el Periódico Oficial del Estado núm. 115, 4ª sección, de fecha 25 de junio de 2014. Disponible en: https:/www.iepcchiapas.org.mx/legislacion/324-constitucion-politicadel-estado-libre-y-soberano-de-chiapas (consultado el 5 de marzo de 2016).

${ }^{13}$ Un dato empírico a destacar es la publicación de noticias sobre los tópicos violencia/política/género que en promedio alcanzan las doscientas notas de internet a la semana para el estado de Chiapas. La búsqueda fue realizada en Google Trends, considerada la herramienta de acceso libre más exacta para conocer el tráfico de contenido en la red por tema, región y temporalidad. Para esta investigación se tomaron en cuenta los 96 relatos más significativos por su oportuna aparición, de los cuales para esta investigación se utilizaron los relacionados con las cuatro categorías de análisis propuestas.

${ }^{14}$ Para el año 2013, en el estado de Chiapas el 34.3\% de los hogares contaba con internet, aunque el uso de computadoras sólo llegaba al $26.4 \%$ y el de telefonía celular al $47.8 \%$. El uso de internet por celular es 
importante en esta región y tiene una pronta asimilación aun cuando los tres indicadores estén por debajo del promedio (INEGI, 2014).

${ }^{15}$ De ellas, veintinueve no estaban en el primer registro de candidaturas publicadas el 15 de junio de 2015

${ }^{16}$ Accesorio en virtud de que depende de algo o alguien.

${ }^{17}$ Barreto y colaboradores (2009) señalan que, en los conflictos de tipo político, el discurso tiene un objetivo abiertamente ideológico, ya que está dirigido a difundir, enseñar y mantener ciertas creencias con el propósito de fortalecer la permanencia de los miembros al grupo y definir la identidad y la posición del grupo en la sociedad.

\section{Referencias bibliográficas}

ACOBOL (s.f.). Bolivia. Violencia política por razón de género. La Paz: ACOBOL

Aparicio Castillo, Francisco Javier (2011). Cuotas de género en México. Candidaturas y resultados electorales para diputados federales2009. México: Tribunal Electoral del Poder Judicial de la Federación, 201l. Disponible en: http://www.te.gob. $\mathrm{mx} /$ documentacion/publicaciones/Temas_selectos/18 cuotas.pdf (consultado el 4 de marzo de 2016).

Arendt, Hannah (1998). La condición humana. México: Paidós.

Báez Carlos, Adriana del Rosario (2014). “iQuiénes votaron en México por mujeres para legisladoras federales en 2012?" En Estudios Políticos, 31: 11-36.

Barrera, Dalia (1998a). "La participación política de las mujeres en México”. En Mónica Verea y Graciela Hierro (eds.), Las mujeres en América del Norte al fin del milenio. México: PUEG/CISAN, pp. 289-298.

Barrera, Dalia (1998b). "Mujeres que gobiernan municipios: un perfil". En Dalia Barrera y Alejandra Massolo (coords.), Mujeres que gobiernan municipios. México: PIEM/COLMEX, pp. 91-112

Barreto, Idaly et al. (2009). "La legitimación como proceso en la violencia política, medios de comunicación y construcción de culturas de paz". En Universitas Psychologica, 8(3): 737-748.

Cámara de Diputados (2015). "Integración por género y grupo parlamentario". Disponible en: http://sitl
diputados.gob.mx/LXII_leg/cuadro_genero.php (consultado el 7 de octubre de 2015).

Canseco, Alberto (2015). "Reconocer la violencia". En Sexualidad, Salud y Sociedad-Revista Latinoamericana, 19: 133-148.

Castro, Inés (2001). "Procesos organizativos y movimientos de mujeres en Chiapas. Un panorama contemporáneo". En Anuario 2001. Centro de Estudios Superiores de México y Centroamérica. Tuxtla Gutiérrez: Universidad de Ciencias y Artes de Chiapas, pp. 203-220.

Castro, Roberto (2012). "Problemas conceptuales en el estudio de la violencia de género. Controversias y debates a tomar en cuenta". En N.B. Tavira y G.V. Bautista (eds.), Violencia, género y la persistencia de la desigualdad en el Estado de México. Buenos Aires: Mnemosyne, pp. 17-38.

Cerva Cerna, Daniela (2014). "Participación política y violencia de género en México". En Revista Mexicana de Ciencias Políticas y Sociales, 59(222): 117-140.

Congreso del Estado de Chiapas. LXVI Legislatura (2015). "Honorable Congreso del Estado de Chiapas". Disponible en: http://congresochiapas. gob.mx/legislaturalxvi/ (consultado el 20 de octubre de 2015)

Coutiño, Fabiola y Julia Hernández (2010). "La inequidad en los espacios de representación popular como una expresión de la otredad: el dilema de las cuotas de género". En Revista del Instituto de Ciencias Jurídicas de Puebla A.C., IV(26): 252-265.

De Lauretis, Teresa (1989). "La tecnología del género". Disponible en: http://blogs.enap.unam.mx/asignatura/ adriana raggi/wp-content/uploads/2013/12/teconologiasdel-genero-teresa-de-lauretis.pdf (consultado el 3 de febrero 2016).

De los Santos, Sandra (2015). "Desplazan a mujeres de algunas comisiones del Congreso del Estado". En Chiapas Paralelo, 15 de octubre. Disponible en http:// chiapasparalelo.com/.../desplazan-a-mujeres-dealginas-comisiones-del-congreso.

Delgado, Rafael (2016). "La paridad de género en las elecciones locales 2015 de Tabasco, Estado de México y Distrito Federal". En LiminaR. Estudios Sociales y Humanísticos, 14(1): 186-201. 
Fernández, Ana (2014). "Mujeres candidatas en la mira: percepciones y representaciones ciudadanas". En Revista Mexicana de Sociología, 76: 59-88.

García, Carlos (2015). "Ordena TEPJF respetar paridad de género en candidaturas de Chiapas". En El Universal, 8 de julio. Disponible en: http://www.eluniversal.com.mx/ articulo/nacion/politica/2015/07/8/ordena-tepjf-respetarparidad-de-genero-en-candidaturas-de (consultado el 10 de noviembre de 2015).

Gobierno del Estado de Chiapas (2015). "Directorio de funcionarios". Disponible en: http://www.chiapas. gob.mx/funcionarios/estatal/ejecutivo (consultado el 21 de octubre de 2015).

Groebel, Jo (1999). "La violencia en los medios: estudio global de la UNESCO”. En Boletín Proyecto Principal de Educación en América Latina y El Caribe, 49: 5-26.

Hernández, David (2015). "Sitian el IEPC en Chenalhó”. En Noticias. Voze Imagen de Chiapas, 23 de julio. Disponible en: http://nvi.mx/sitian-el-iepc-en-chenalho/ (consultado el 10 de noviembre 2015).

IEPC (Instituto de Elecciones y Participación Ciudadana) (2015). "Relación de mujeres electas como presidentes municipales para el periodo 20152018". Disponible en: https://www.iepc-chiapas.org. $\mathrm{mx} /$ archivos/resultados_finales_elecciones_2015/ AYUNTAMIENTOS_nombres_ok2.pdf (consultado el 4 de noviembre de 2015).

INEGI (Instituto Nacional de Estadística y Geografía) (2014). Estadísticas sobre disponibilidad y uso de tecnología de información y comunicaciones en los hogares, 2013. México: INEGI.

INE (Instituto Nacional Electoral) (2016a). "Acuerdo del consejo general del instituto nacional electoral por el que, en ejercicio de la facultad de atracción, se emiten criterios generales a efecto de garantizar el cumplimiento al principio de paridad de género en la postulación de candidaturas para todos los cargos de elección popular a nivel local”. Disponible en: http://www.ine.mx/archivos3/portal/historico/ recursos/IFE-v2/DS/DS-CG/DS-SesionesCG/CGacuerdos/2016/02_Febrero/CGex201602-08_02/ CG2e201602-08ap2.pdf (consultado el 28 de febrero de 2016).
INE (Instituto Nacional Electoral) (2016b). "Acuerdo del consejo general del instituto nacional electoral por el que en ejercicio de la facultad de atracción, se establecen los criterios generales para normar la realización de los cómputos municipales, distritales y de entidad federativa de los procesos electorales ordinarios locales 2015-2016, así como en su caso, los extraordinarios que resulten de los mismos". Disponible en: http://www. ine.mx/archivos3/portal/historico/recursos/IFE-v2/ DS/DS-CG/DS-SesionesCG/CG-acuerdos/2016/03 Marzo/CGex201603-30_2a/CG2ex201603-30_ap_2. pdf (consultado el 28 de febrero de 2016).

INE (Instituto Nacional Electoral) (2016c). "Informe Anual de Actividades de la Comisión del Registro Federal de Electores en el año 2015”. Disponible en: http://ine.mx/archivos2/DS/recopilacion/CG.ex20160127in_01Pll-05.pdf (consultado el 28 de febrero de 2016).

Lagarde, Marcela (1997). Género y feminismo. Desarrollo humano y democracia. Madrid: Horas y Horas.

Mariscal, Ángeles (2015). "Juanitas en Chiapas cumplen paridad de género con esposas y hermanas". En CNN, 15 de julio de 2015. Disponible en: http://mexico.cnn. com/adnpolitico/2015/07/15/Juanitas-en-chiapascumplen-paridad-de-genero-con-esposas-y-hermanas (consultado el 14 de octubre de 2015).

Martínez Vergara, Paola (2007). "Reflexiones en torno a la ley general de acceso de las mujeres a una vida libre de violencia". En Revista del Posgrado en Derecho de la UNAM, 3(5): 237-256.

Martínez, Piedad (2006). "El método de estudio de caso: estrategia metodológica de la investigación científica". En Pensamiento y Gestión: Revista de la División de Ciencias Administrativas de la Universidad del Norte, 20: 165-193.

Massolo, Alejandra (2003). "Participación de las mujeres en los gobiernos locales de América Latina”. En Dalia Barrera y Alejandra Massolo (coords.), Memoria del Primer Encuentro Nacional de Presidentas Municipales. México: INMUJERES, pp. 1-19.

Medina Espino, Adriana y Ruth Gisela Benítez Márquez (2010). La participación política de las mujeres: De las cuotas de género a la paridad. México: Centro de Estudios para el Adelanto de las Mujeres y la Equidad de Género. 
Muñoz, Patricia (2011). Violencias interseccionales. Debates feministas y marcos teóricos en el tema de la pobreza y violencia contra las mujeres en Latinoamérica. Tegucigalpa: CAWN.

OEA (1996). "Convención Interamericana para Prevenir, Sancionar y Erradicar la Violencia contra la Mujer". Disponible en: http://www.cndh.org.mx/sites/all/ doc/programas/mujer/Material_difusion/convencion BelemdoPara.pdf (consultado el 8 de octubre de 2015).

Peschard, Jaqueline (2003). "Medio siglo de participación política de la mujer". En Revista Mexicana de Estudios Electorales, 2: 13-33.

Pérez Robledo, Flor María (2004). "Pegar 'de balde'/ pegar 'con razón'. Aproximación etnográfica a las prácticas violentas hacia mujeres en comunidades tojolabales". En Teresa de Juan Fernández (coord.), Violencia contra la mujer en México. México: Comisión Nacional de Derechos Humanos, pp. 5l-68.

Pérez, Gonzalo (2015). "Toma posesión esposo de alcaldesa electa”. En Diario Meridiano 90. Disponible en:http://www. diariomeridiano90.com/index.php/lasnoticias/11618 toma-posesion-esposo-de-alcaldesa-electa (consultado el 7 de octubre de 2015).

Presidencia de la República (2015). "Gobierno. Gabinete". Disponibleen:http://www.presidencia.gob.mx/gabinetearea/gabinete/ (consultado el 7 de octubre de 2015).

Rodríguez, Candelaria (2015). "Agresiones a mujeres candidatas y el sombrío panorama de ser esposas". En SEM México. Servicio Especial para la Mujer. Disponible en: http://www.semmexico.org/agresionesa-mujeres-candidatas-y-el-sombrio-panorama-por-seresposas/ (consultado el 17 de julio de 2015).
Rojas, María (2012). “Acoso y violencia política en razón de género afectan el trabajo político y la gestión pública de las mujeres". En Revista Derecho Electoral, 13: 248-258.

Scott, Joan (1996). "El género: una categoría útil para el análisis histórico”. En Marta Lamas (coord.), El género: la construcción cultural de la diferencia sexual. México: PUEG/Porrúa, pp. 265-302.

Senado de la República. LXIII Legislatura (2015a) "Senadoras". Disponible en: http://www.senado. gob.mx/index.php? ver=int\&mn=4\&sm=2\&str=M (consultado el 7 de octubre de 2015).

Senado de la República (2015b). "Versión sesión ordinaria 21 de abril de 2015". Disponible en: http://comunicacion. senado.gob.mx/index.php/informacion/versiones/20373version-sesion-ordinaria-21-de-abril-de-2015.html (consultado el 7 de octubre de 2015).

Serret, Estela (2008). Discriminación de género. Las inconsecuencias de la democracia. México: Consejo Nacional para Prevenir la Discriminación.

Valles, Miguel (2000). Técnicas cualitativas de investigación social. México: Síntesis.

Vázquez, Cosme (2015). "Mirna Camacho espera logro de ley contra violencia política hacia las mujeres". En Areópago, 15 de julio. Disponible en: http://www. areopago.mx/feminismo/2998-mirna-camacho-esperalogro-de-ley-contra-la-violencia-politica-hacia-lasmujeres (consultado el 7 de octubre de 2015).

Victorio, Diego (2015). "El Verde cede Unión Juárez y Villa Comaltitlán”. En AquíNoticias, El Portal de la Esfera Pública, 15 de julio de 2015. Disponible en: http:// aquinoticias.mx/desde-mi-trinchera-diego-victorio-29/ (consultado el 7 de octubre de 2015). 